\title{
TNFA deletion alters apoptosis as well as caspase 3 and 4 expression during otitis media
}

\author{
Joerg Ebmeyer ${ }^{1 \dagger}$, Anke Leichtle ${ }^{2 \dagger}$, Michelle Hernandez ${ }^{3}$, Umay Ebmeyer ${ }^{4}$, Jacob Husseman ${ }^{2}$, Kwang Pak $^{2}$, \\ Holger Sudhoff', David Broide ${ }^{3}$, Stephen I Wasserman ${ }^{3^{*}}$, Allen F Ryan ${ }^{2^{*}}$
}

\begin{abstract}
Background: Tumor necrosis factor (TNFA) is the canonical member of the TNF superfamily, which plays a major role in both inflammation and apoptosis. To evaluate the role of TNFs in otitis media (OM), the most common disease of childhood, we evaluated middle ear (ME) expression of genes encoding the TNF and TNF receptor superfamilies during bacterial OM in the mouse, characterized OM in TNFA-deficient mice, and assessed apoptosis during OM in normal versus TNF-deficient MEs.

Results: TNFs and TNF receptors were broadly regulated during OM, with TNFA showing the highest level of upregulation. TNF deficient mice exhibited mucosal hyperplasia even in the absence of infection and exuberant growth of the mucosa during $\mathrm{OM}$, including the formation of mucosal polyps. Mucosal recovery during OM was also delayed, in parallel with a delay in mucosal apoptosis and reduced caspase gene expression.

Conclusions: The TNF and TNF receptor superfamilies mediate both inflammation and apoptosis during OM. TNF appears to be critical for the maintenance of mucosal architecture in both the normal and infected ME, since excessive accumulation of mucosal tissue is seen in TNFA ${ }^{-/}$MEs both before and after bacterial inoculation of the ME. TNFA is also required for appropriate regulation of caspase genes.
\end{abstract}

\section{Background}

Tumor necrosis factor (TNFA, TNFSF2), formally known as TNF $\alpha$, is a pleiotropic cytokine widely involved in apoptosis as well as cell proliferation, immune and inflammatory reactions. It is produced by activated macrophages and mast cells, and also by epithelial and stromal cells. TNFA is the founding member of the TNF superfamily, now composed of more than 20 members. Through interaction with their large family of cognate TNF receptors (TNFRs), TNFs can activate transcription factors such as NF- $\kappa \mathrm{B}$ and c-Jun, which modulate expression of genes related to apoptosis and various other cellular responses, or via TNFR death domains which can directly stimulate cell death [1-5].

\footnotetext{
* Correspondence: swasserman@ucsd.edu; afryan@ucsd.edu + Contributed equally

${ }^{2}$ Department of Surgery, Division of Otolaryngology, University of California, San Diego School of Medicine and Department of Veterans Affairs Medical Center, La Jolla, California, USA

${ }^{3}$ Department of Medicine, Division of Rheumatology, Allergy and Immunology, UCSD School of Medicine, La Jolla, California, USA Full list of author information is available at the end of the article
}

Together with interleukin-1 $\beta$, TNFA is considered one of the primary cytokines of middle ear (ME) inflammation [6]. In the early stage of inflammation, TNFA is produced by the ME mucosa and in the late stage also by accumulating inflammatory cells. TNFA is induced by bacterial pathogens, both Gram-positive and Gramnegative and it participates in viral otitis media $(\mathrm{OM})$ [7-9]. Elevated levels of TNFA in the ME fluids of patients with OM are very common [10]. In rat and mouse models of acute OM, the expression of TNFA transcripts in the ME mucosa increased substantially within six hours after challenge with nontypeable Haemophilus influenzae (NTHi) [11,12]. However, the expression of most other TNF family members and of TNF receptors has not been extensively documented in OM.

TNFA has been demonstrated to up-regulate mucin genes in the ME epithelium [13] and thus probably plays an essential role in the pathogenesis of mucoid OM. Transtympanic injection of TNFA into normal MEs causes OM [14], which can be attenuated by simultaneous administration of TNF soluble receptor type I

\section{() Biomed Central}


(TNFsolRI) [15]. Anti-TNFA antibodies have been suggested as a treatment option for OM (reviewed by Smirnova et al. [6]). However, we have previously shown that mice lacking TNFA show a failure to clear bacteria from the ME, accompanied by abnormalities in phagocytosis and intracellular killing by macrophages, and delayed OM resolution [12]. All these findings indicate a broad involvement of TNFA in the inflammatory reaction during OM.

TNFA also plays a major role in apoptosis. Given the delayed resolution of OM observed in TNFA-deficient mice [12], this raises the question of whether TNFA's apoptotic function might contribute to remodeling of the ME mucosa as well as its return to normal structure during recovery from OM. Supporting this concept, dysregulation of TNFA signaling has been reported to be involved in the pathogenesis of nasal polyposis [16] as well as colon polyps [17], reflecting the apoptotic effects of TNFA and alterations of the epithelial architecture due to the accumulation of excess mucosal cells in its absence. Several other members of the TNF and TNFR families are also involved in apoptosis [4,5]. Very few studies have addressed the role of apoptosis, including TNF-mediated cell death, in OM, although it has been demonstrated that mice lacking TNFR6, also known as Fas, show delayed recovery from bacterial OM [18].

To explore the role of the TNF superfamily in regulating apoptosis during $\mathrm{OM}$, we used gene arrays to evaluate the expression of genes encoding all members of the TNF and TNFR superfamilies during NTHi-induced $\mathrm{OM}$ in the mouse. In addition, we induced bacterial OM [19] in $\mathrm{TNFA}^{-1-}$ and wild-type (WT) mice. We determined the effects of TNFA deletion on mucosal hyperplasia and remodeling as well as upon the course of apoptosis within the ME mucosa during the course of a ME infection.

\section{Results}

\section{Expression of TNF and TNFR genes}

Of the 23 known TNF superfamily genes, 7 were significantly regulated during OM, as illustrated in Figure 1A, and in the Additional File 1, Table S1. The Tnfa gene itself was strongly and significantly up-regulated from 25 -fold to more than 100 -fold over the period from 3 hours to 3 days after NTHi inoculation, and 2-fold at day 5 , when compared to uninoculated $(0 \mathrm{hr})$ controls. $\operatorname{Tnf} 14$ was up-regulated up to 25 -fold, the Tnf9 gene over 5 -fold, and Tnf13b up to 3-fold, over a similar time course. Tnf11 was more briefly up-regulated more than 6-fold from 3-24 hours, while Tnf10 was up-regulated more than 2-fold at 6 hours and, in contrast to the other genes, remained so throughout the experiment. Only one gene, Tnf4, was down-regulated with expression decreased to $\sim 30 \%$ of that seen in the control ME 1 and
2 days after NTHi inoculation. Thus, all three TNF family genes with known pro-apoptotic functions (Tnfa, Tnf9 and $T n f 10$ ) and one TNF gene with anti-apoptotic function (Tnf11) were up-regulated during OM.

Eleven members of the TNFR superfamily were regulated during $\mathrm{OM}$, as illustrated in Figures $1 \mathrm{~B}$ and $1 \mathrm{C}$, and in the Additional File 1, Table S1. While the Tnfr1a and Tnfr 18 genes were significantly up-regulated from 6 hours to 2 days, the Tnfr $1 b$, Tnfr 9 , and Tnfr $12 a$ genes were much more strongly up-regulated from 3 hours to 3 days. While increasing with a similar pattern, Tnfr5 and Tnfr $11 b$ mRNA appeared to remain elevated until 7 days. Tnfr 22 and Tnfr 23 mRNAs were not up-regulated until 1 day after inoculation, and then decreased rapidly. Tnfr $13 b$ and Tnfr 19 were also up-regulated relatively late, but remained elevated even at 5 and 7 days after ME infection. Down-regulation of TNFR genes was rare, with only Tnfr $1 a$ and Tnfr 23 showing significantly reduced expression at 7 days. Thus, of the TNF receptor genes with known pro-apoptotic function, Tnfrla, Tnfrlb, and $\operatorname{Tnfr} 9$ were up-regulated, as was the anti-apoptotic receptor gene Tnfr11b.

\section{Middle Ear Histology}

As we have described previously [20-22] in WT mice ME mucosal hyperplasia was observed starting on day 1 and peaked on day 2 after NTHi inoculation. On day 3 the ME mucosa remained significantly hyperplastic, but by day 5 it had recovered to near normal thickness (Figure 2). When the mucosa was divided into its epithelial and stromal compartments however, as shown in Figure 3A and 3B, recovery of epithelial thickness was not complete until day 10, while the stroma had recovered by day 5 . The proportion of the ME mucosa occupied by infiltrating leukocytes was highest on day 1 , and decreased regularly until few cells were observed on day 5 and virtually none on day 7 .

A significant difference between $\mathrm{TNFA}^{-/-}$mice and WT mice was observed even in untreated animals: both epithelial and stromal compartments of the ME mucosa were significantly hyperplastic in the absence of TNFA (Figures 2, 3A,B). Thereafter, the mucosa of both WT and TNFA $^{-1-}$ increased when compared to uninoculated animals $(p<.05)$, such that significant differences between WT and $\mathrm{TNFA}^{-1-}$ mice in the thickness of the ME mucosa epithelium or stroma were not observed until day 5 after infection. As noted above, the epithelium of the WT mice began to return to its normal thickness on day 5 and was normal by day 10, while the epithelium of the TNF knockout (KO) mice remained hyperplastic. The ME mucosal stroma of the TNFA ${ }^{-/-}$ animals showed no decrease in thickness on day 5 , but did recover somewhat on day 7 . However, it remained significantly thicker than the WT even on day 10 . 


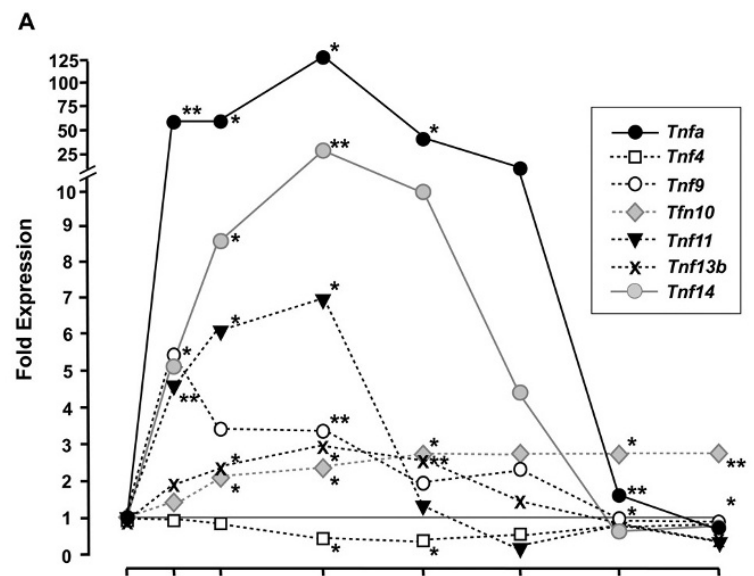

B

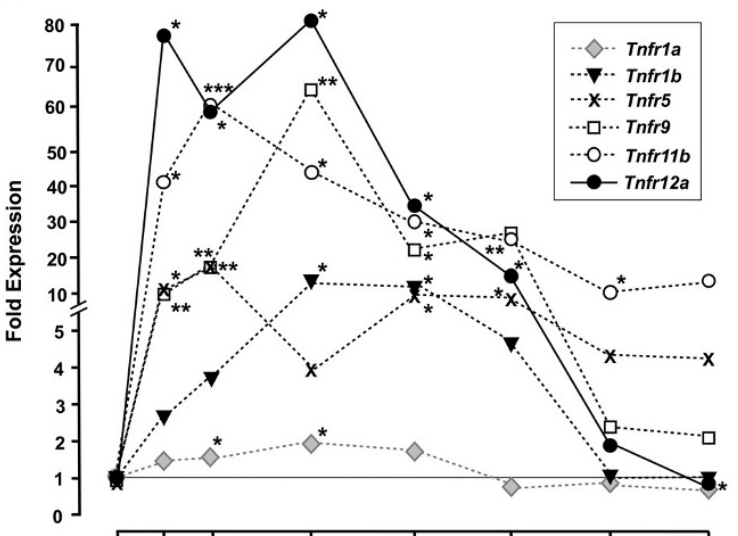

C

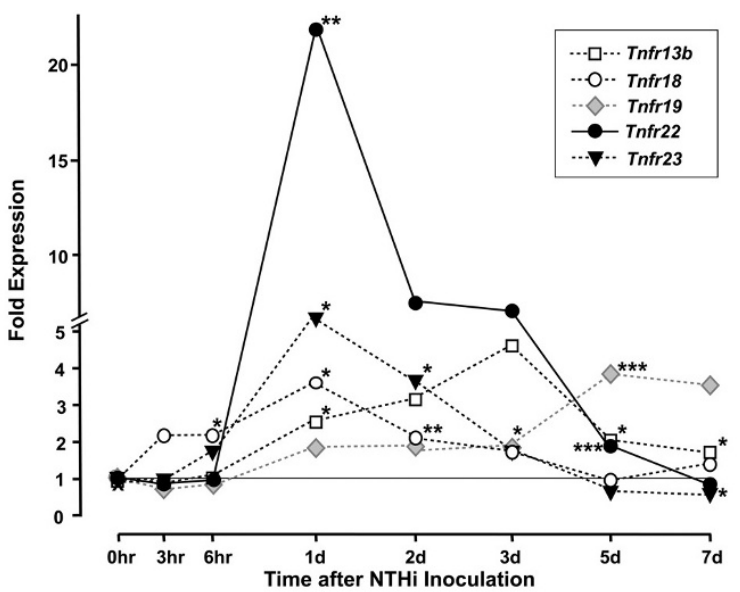

Figure 1 Relative expression of TNF and TNF receptor superfamily genes during acute OM in the mouse. A. mRNA encoding genes of the 23-member TNF superfamily in the ME mucosa was evaluated on Affymetrix whole-genome gene arrays. Data are expressed as fold induction over untreated ME mucosa $(0 \mathrm{~h})$. Only significantly regulated genes are shown. Each data point represents gene arrays obtained from 2 independent sets of 20 C57BL/6J mice each. B,C. Relative expression of TNF receptor superfamily genes during acute OM in the mouse. Significantly regulated members of this large (29 member) gene family are represented in the two panels of this figure. $=\mathrm{P}<.05 ;{ }^{* *}=\mathrm{P}<.01$; ${ }^{* * *}=P<.001$. 


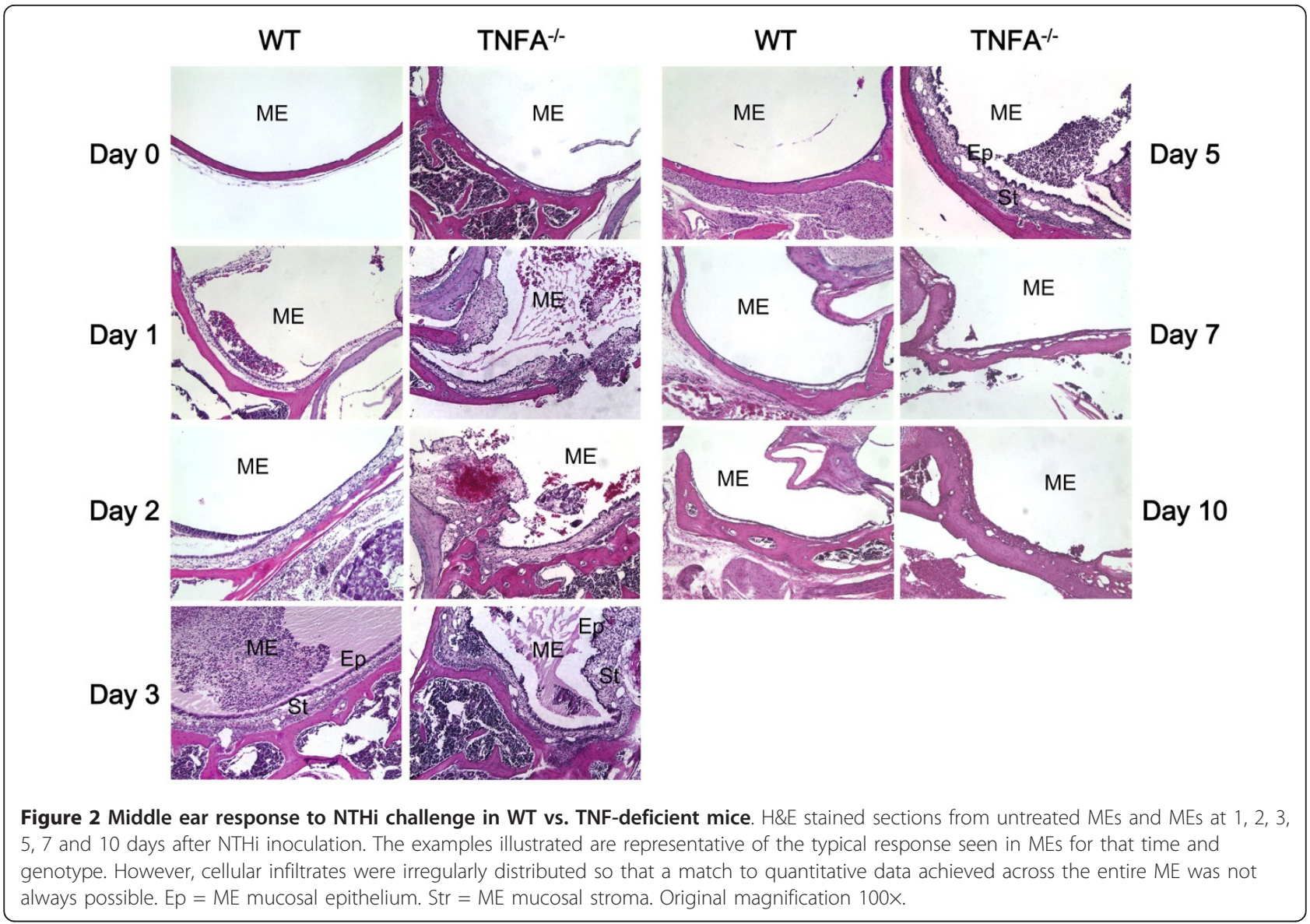

While the thickness of the TNFA ${ }^{-1-}$ ME mucosa in most areas was similar to that in WTs from 1-5 days after inoculation, localized increases in thickness were observed in $\mathrm{TNFA}^{-1-}$ mice. Challenge with NTHi resulted in the formation of mucosal polyps in a high percentage of MEs of TNFA ${ }^{-1-}$ mice from 1-7 days after infection. In WT mice, polyp formation was observed in only one ME, on day 1 post infection. Unchallenged animals, either WT or TNFA-deficient, did not exhibit mucosal polyps (Figure 4A and 4B).

Lack of TNF also influenced infiltration of the ME by leukocytes. In $\mathrm{TNFA}^{-1-}$ animals, more cells entered the ME. Moreover, apparently viable leukocytes were present in the ME for a longer period (Figure 5A). This difference reached significance by day 5 , and remained so on day 10. In addition, the character of the cells was also different (Figure 5B). Almost all of the cells observed in the WT ME on day one were neutrophils, as we have noted previously [12]. In contrast, significant numbers of macrophages were observed in the TNFA ${ }^{-1-}$ MEs, at this time. Moreover, by day 5 when macrophages dominated the few cells remaining in the WT $\mathrm{ME}, \mathrm{TNFA}^{-1-}$ MEs contained a high proportion of neutrophils.

\section{Apoptosis}

The time course of apoptosis in the ME mucosa of WT mice, represented by the percentage of TUNEL-positive cells, is illustrated in Figure 6. Apoptotic cells were observed in the mucosal epithelium and stroma (Figure $6 \mathrm{~A})$ as well as among infiltrating leukocytes. As expected, counts of apoptotic cells (Figure 6B) revealed a low level of baseline level of apoptosis even in the uninfected WT ME. This was maintained during OM, but showed a single significant peak on day 5 after infection, at the time when mucosal thickening was returning to baseline. In the absence of TNF, increased apoptosis was delayed until 7 days post infection, and remained significantly higher than observed in WTs at 10 days.

To further address the mechanism of changes in apoptosis, we evaluated, using qPCR (Figure 7), the expression of the primary effector caspase, caspase 3 , and caspase 4 which serves both inflammatory and apoptotic roles [23,24]. Expression of both caspases was low in uninfected WT MEs. Following ME infection, no change in caspase 3 mRNA was noted until day 5, when expression was up-regulated before returning to its original level by day 10 . Caspase 4 


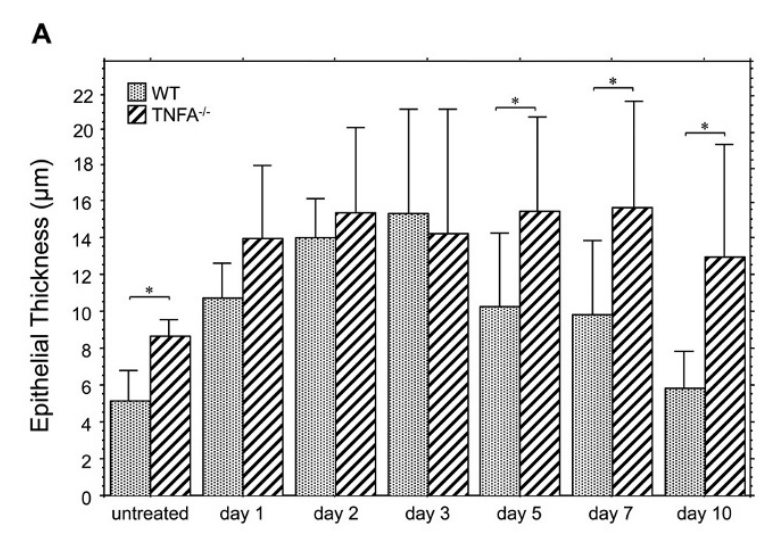

\section{B}

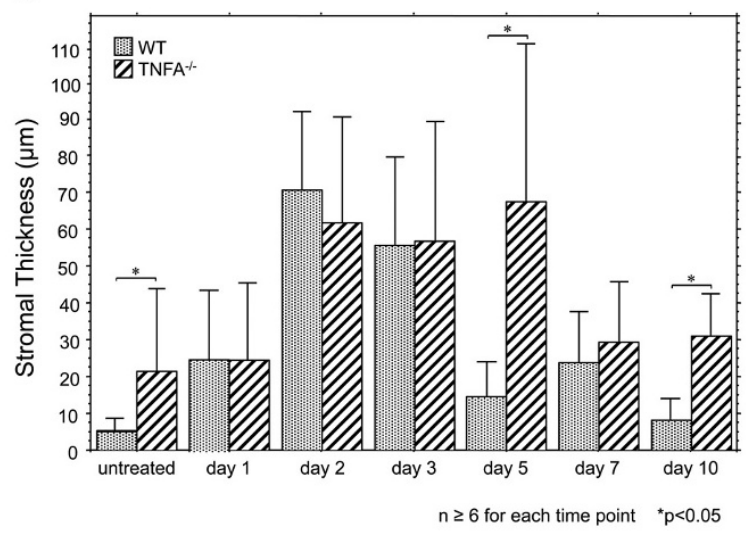

Figure 3 Thickness of the ME mucosa of WT vs. TNFA ${ }^{-1-}$ mice during NTHi-induced OM. A. Thickness of the ME mucosal epithelium in WT (stippled bars) and TNFA ${ }^{-1-}$ (striped bars) mice. B Thickness of the mucosal stroma. Bars represent means, while lines represent $1 \mathrm{SD} .{ }^{*}=p \leq 0.05 ; n=6-10$ for each group.

showed a strong peak 6 hours after NTHi inoculation in WT mice, followed by a decline and then a second, albeit lower peak at day 5 . In $\mathrm{TNFA}^{-1-}$ mice, both caspases 3 and 4 were expressed at moderate levels prior to NTHi inoculation. However, after inoculation their expression rapidly decreased to very low levels, and remained so through day 10 .

\section{Discussion}

The regulation of multiple TNF and TNFR superfamily genes during $\mathrm{OM}$ indicates the importance of these gene families to the disease process and also presumably reflects the pleiotropic nature of TNF/TNFR function. While changes in TNF/TNFR signalling could be mediated by the observed regulation of TNF/TNFR genes, signalling is also likely to be modulated independent of gene regulation through post-translational modification. It is known that post-translational changes in mRNA splicing or in the effector proteins can strongly
A

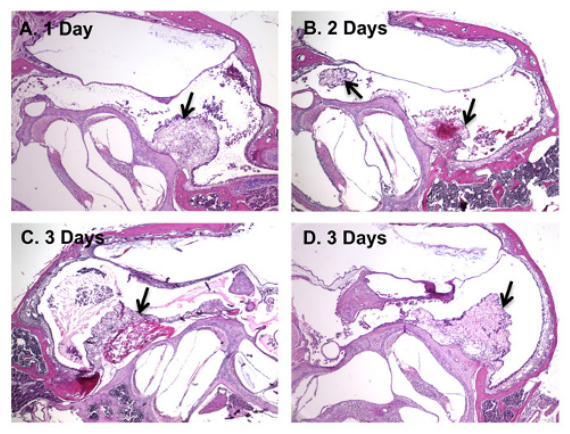

B

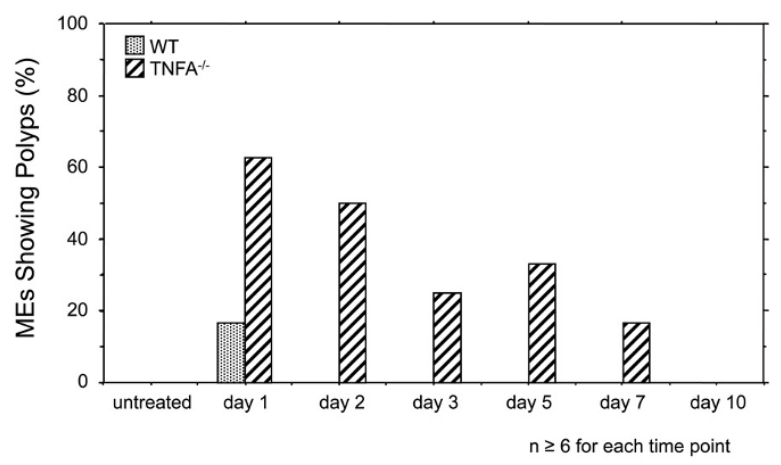

Figure 4 Mucosal polyps in the mucosa of $\mathrm{TNFA}^{-/-}$mice following NTHi challenge. A. Examples of polyps (arrows) in the ME mucosa of TNF KO mice at various intervals after NTHi inoculation. H\&E staining. Magnification $\mathrm{A}-\mathrm{C}=40 \mathrm{x}, \mathrm{D}=80 \mathrm{x}$. B. Percentage of ears in which polyps were found in serial sections. While polyps were common in TNFA ${ }^{--}$MEs, only one polyp was seen in WT animals. $n=6-10$ for each group.

influence TNF/TNFR interactions [4,5], and we acknowledge that our gene array data do not address this point. However, conclusions can be drawn based on the particular TNFs and TNFRs whose genes did exhibit regulation during $\mathrm{OM}$.

Of the TNF superfamily members encoded by genes that were significantly regulated, TNFA and TNF10 (TRAIL) activate TNF receptors (TNFR1a, TNFR1b, TNFR10) that contain death domains $[5,25,26]$, and thus are likely to induce apoptosis. Of the regulated TNFs that activate receptors without a death domain, TNF9 can enhance apoptosis indirectly by inducing prolonged expression of TNF $[27,28]$; TNF11 and TNF14 can be anti-apoptotic [29-31], while others appear to have only non-apoptotic functions (TNF4; T-cell recruitment, proliferation and cytokine production [32]; TNF13B, B-cell activation [33]).

Not all of the genes encoding receptors for the above TNFs were themselves regulated, and conversely some receptor genes were regulated in the absence of gene 


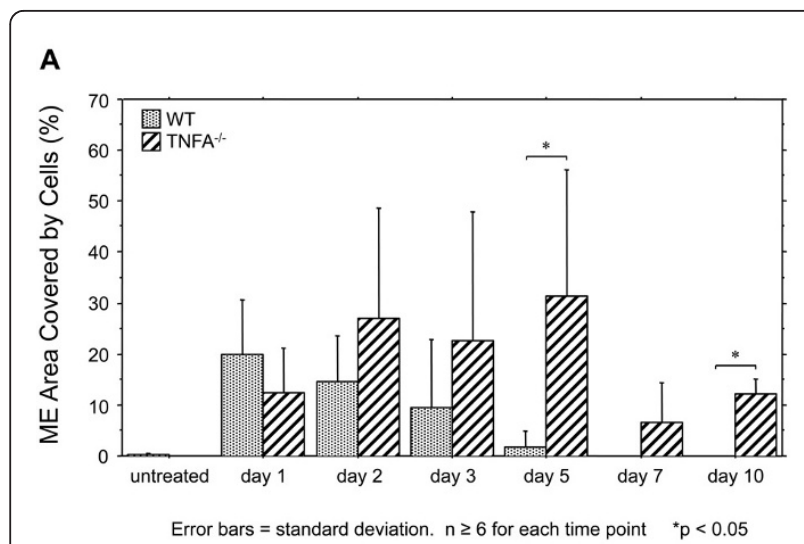

B

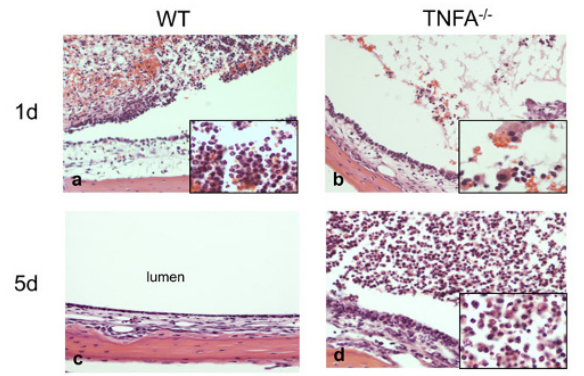

Figure 5 Leukocyte infiltration of the ME during $O M$. A. Percentage of the ME lumen occupied by inflammatory cells after challenge with NTHi in WT (stippled bars) and TNFA ${ }^{-1}$ (striped bars). Bars represent means, while lines represent $1 \mathrm{SD} .{ }^{*}=p \leq 0.05 ; n=$ 6-10 for each group. B. Micrographs representing the typical appearance of cellular infiltrates in the two genotypes at 1 and 5 days after NTHi inoculation. Magnification 150x (insert $=400 \times$ ).

regulation of their ligand. These included TNFR18, which regulates $\mathrm{T}$-cell mediated cell death [34,35], and TNFR19, which can induce apoptosis via JNK signaling [36]. Others encoded decoy receptors that are antiapoptotic, such as TNFR11B, a secreted receptor that can bind TNF10 [37], and membrane-inserted TNFR22 and TNFR23 [38]. Still others encoded receptors with functions unrelated to apoptosis, including TNFR5 (Bcell growth, differentiation and survival [39]) and TNFR12a (angiogenesis [40]).

It might be hypothesized that apoptosis would be inhibited early in OM to support mucosal hyperplasia, and enhanced during OM recovery to remove excess mucosal cells and leukocytes. Indeed, apoptosis as measured by TUNEL labeling peaked in WT mice late in OM. However, apoptosis was also observed early in $\mathrm{OM}$, and indeed in the normal, uninfected ME. Evaluating the time courses of gene expression, the various pro-apoptotic TNF and TNFR genes that are regulated during acute $\mathrm{OM}$ were expressed over its entire time course, beginning at 3 hours and continuing until

\section{A}
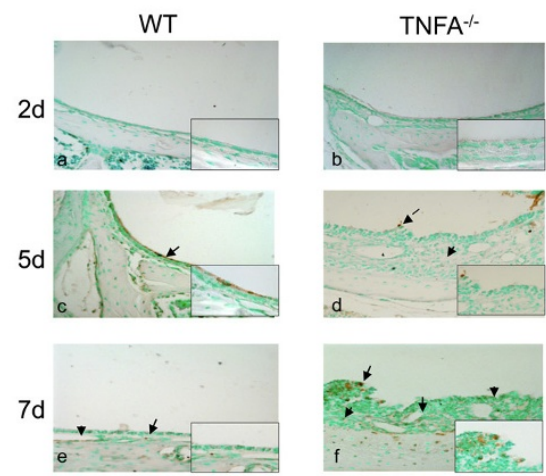

B

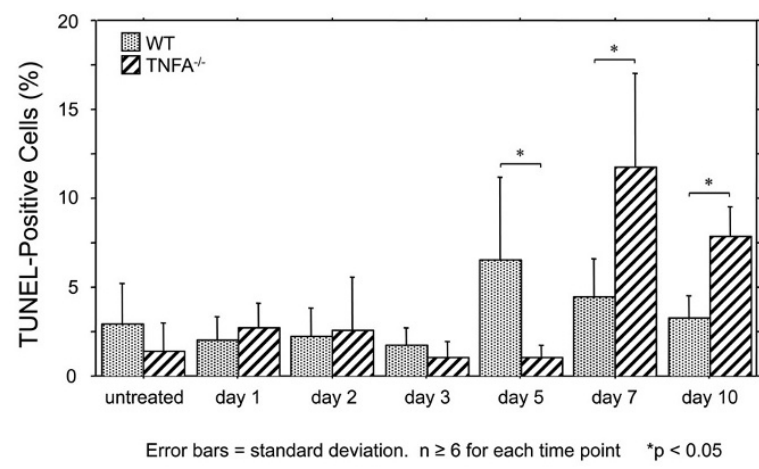

Figure 6 Apoptosis in the ME mucosa during OM. A Micrographs illustrating TUNEL-labeled cells in the ME mucosae of WT versus TNFA ${ }^{-1-}$ mice after inoculation of the ME with NTHi. B. Percentage of apoptotic cells in the ME mucosa following NTHi injection. Values are means $\pm \mathrm{SD}$; asterisks indicate statistical significance $(p \leq 0.05) ; n=6-10$ for each group.

7 days. Thus the genes for Tnfa and its receptors Tnfr $1 a$ and Tnfr $1 b$, Tnf9 and Tnfr 9 , as well as Tnf1r18 are up-regulated early in $\mathrm{OM}$ and decline after day 3 , although Tnfa remained 1.8X up-regulated at day 5 . Tnf10 expression is enhanced throughout $\mathrm{OM}$ and that of Tnfr19 late in OM. Conversely, the various anti-apoptotic genes are also expressed throughout OM. While Tnf11 and Tnf14 are expressed early in OM, Tnfr22 and Tnfr 23 are expressed midway through OM, while Tnfr $11 b$ is up-regulated throughout OM. Of course, the TNFs and their receptors are multifunctional, and no direct relationship between gene expression and apoptosis can be drawn. However, the substrates for both apoptosis enhancement and inhibition were present throughout OM.

During development, apoptosis occurs extensively during tissue remodeling (e.g. [41]), thus it is not surprising that pro-apoptotic genes and apoptosis were observed early in $\mathrm{OM}$ as the ME mucosa remodels to adopt a more respiratory phenotype (e.g. [42]). Also, the 

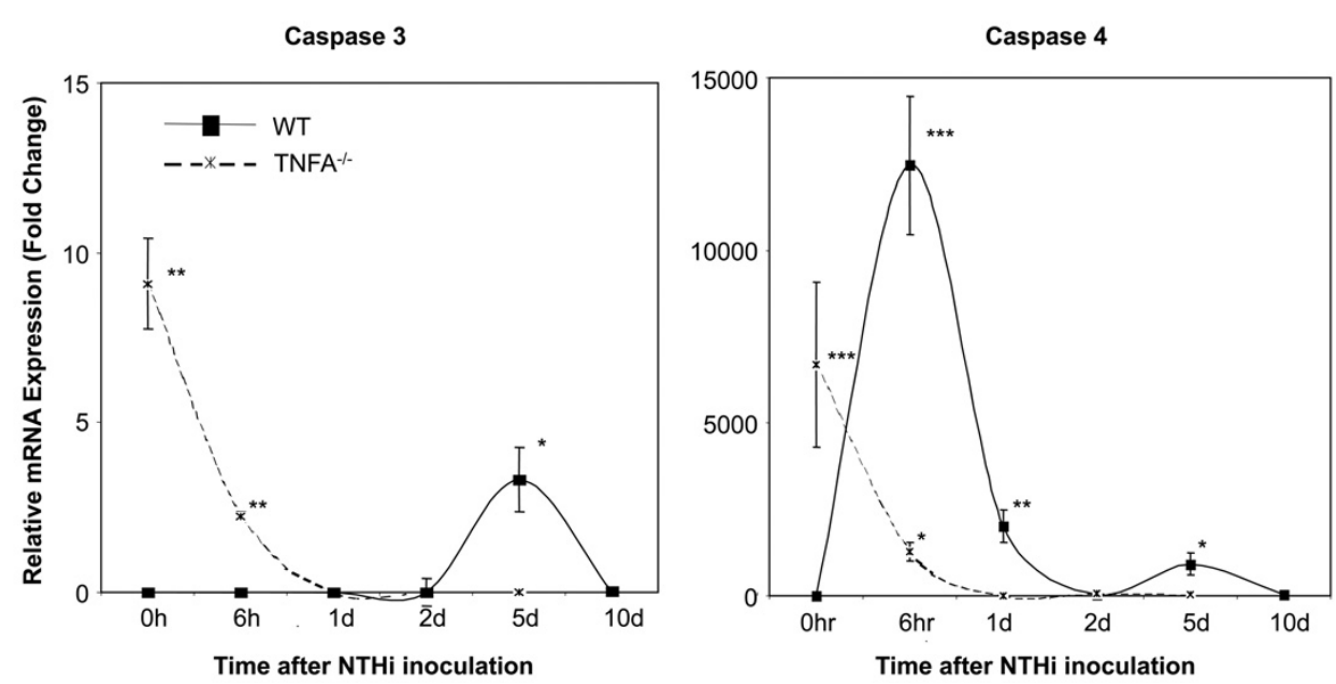

Figure 7 Expression of caspase mRNAs during NTHi-induced OM. In WTs, caspase 3 was expressed only on day 5, while caspase 4 mRNA was expressed at high levels early in $\mathrm{OM}$, and then again at day 5. While both caspases were expressed at high levels in TNFA ${ }^{-1-}$ MEs prior to $\mathrm{OM}$, expression declined rapidly and became undetectable soon after inoculation.

expression of pro- and anti-apoptotic genes throughout $\mathrm{OM}$ is consistent with current concepts of programmed cell death, which must be kept under tight regulation to prevent unwanted loss of cells [e.g. [43,44]]. The peak of TUNEL labeling observed at 5-10 days after NTHi inoculation in WT mice presumably reflects an increase in factors favoring apoptosis and a decrease in antiapoptotic factors. To the extent that TNFs and TNFRs are responsible, pro-apoptotic TNFA and TNF10 (TRAIL) and TNF19 are good candidates to enhance apoptosis late in OM, while TNFR11B could negatively regulate apoptosis during OM recovery. The increase in TUNEL labeling in the ME mucosa coincides with late changes in the expression of caspase 3 and caspase 4 as observed in the qPCR data from the WT ME on day 5 after inoculation.

Absence of the TNFA gene during bacterial OM had profound effects upon the architecture of the ME mucosa, infiltration of the ME by leukocytes, and apoptosis. Even prior to infection, the ME mucosa was hyperplastic in TNF KO mice, perhaps reflecting reduced apoptosis in the resting ME resulting in the accumulation of excess tissue due to altered homeostatic remodeling. However, while the amount of apoptosis observed in the TNF KO ME mucosa was lower than that seen in the WT ME (Figure 6B), this difference was not statistically significant. Alternatively, hyperplasia in the TNF KO ME could reflect low-grade infection with endogenous microorganisms in the absence of this critical cytokine. We have previously shown that TNFA is critical to bacterial clearance in the ME, and that macrophages of $\mathrm{TNFA}^{-/-}$mice display impaired phagocytosis and intracellular killing of NTHi. In fact, we cultured bacteria from the MEs of naïve $\mathrm{TNFA}^{-1}$ mice on chocolate agar (data not shown). However, we could not identify the organisms and can only speculate regarding their role.

While the ME mucosa of uninfected $\mathrm{TNFA}^{-/-}$mice was significantly thicker than that of WTs, NTHi inoculation nevertheless resulted in significant additional mucosal growth in TNFA ${ }^{-1-}$ animals when compared to the pre-inoculation state. Hyperplasia of the majority of the $\mathrm{TNFA}^{-1-}$ ME mucosa that occurred after NTHi inoculation was not significantly different from that seen in WTs for the first few days, suggesting that TNFA does not play a role in initial hyperplasia. An exception was the development of mucosal polyps, which was observed as early as 1 day after inoculation. However, recovery of the mucosa to normal thickness was significantly delayed by lack of TNFA (Figures 2 and 3). The reduced apoptosis observed in the ME mucosa of $\mathrm{TNFA}^{-1-}$ mice on day 5 , when compared to WTs, seems likely to contribute to both the persistence of mucosal thickness and the development of mucosal polyps (Figure 4). While at later times TNFA ${ }^{-1-}$ animals showed higher levels of apoptosis, this may reflect the fact that recovery is complete in the WT ME, while delayed recovery from hyperplasia continues in $\mathrm{TNFA}^{-1-}$ mice. This finding suggests that impaired recovery from ME inflammation in $\mathrm{TNFA}^{-1-}$ mice, as found by Leichtle et al. [12] may be the primary reason for persistent $\mathrm{ME}$ mucosal thickness in TNFA ${ }^{-1-}$ mice. The lack of caspase 3 and 4 up-regulation on day 5 in $\mathrm{TNFA}^{-1-}$ mice, when compared to WTs, also seems likely to reflect this 
general prolongation of hyperplasia and inflammation. The observation of increased apoptosis on days 7 and 10 (Figure 6B) further suggests that alternative mechanisms for production of mucosal apoptosis must be active in the MEs of $\mathrm{TNFA}^{-/-}$mice, perhaps mediated by other pro-apoptotic members of the TNF superfamily such as TNF10 or, given the results of Rikvin et al. [18], TNF6 (Fas). This apoptosis appears directed at recovery of the ME mucosa, since the delayed peak in apoptosis in $\mathrm{TNFA}^{-/-}$mice 7 days post infection correlates with the time of regression of mucosal polyps (Figure 4).

The prolonged presence of leukocytes in the MEs of $\mathrm{TNFA}^{-1-}$ mice is very unlikely to involve lack of TNFAmediated apoptosis, as TNFA does not appear to mediate cell death in leukocytes. Neutrophils die by an intrinsic program of apoptosis, approximately three days after differentiation, that does not require death ligands [45], while apoptosis of other classes of leukocytes involve alternative TNFs such as TNF6 (Fas). Prolonged inflammation leading to enhanced leukocyte recruitment or lower levels of leukocyte clearance via vessels seem more likely, since TNFA has been shown to be involved in leukocyte trafficking in other systems [46].

Of course, our results are specific to NTHi-induced OM. However, given the similarity or OM induced by NTHi and pneumococcus in the mouse [19], and the central role of TNFA in both inflammation and apoptosis, similar effects of TNFA deletion might be observed in OM induced by pneumococcus and perhaps other ME pathogens.

\section{Conclusions}

The results of the present study suggest that the TNF and TNF receptor superfamilies play important roles in OM, mediating both inflammation and apoptosis. TNFA appears to be a critical factor for the maintenance of mucosal architecture in both the normal and infected ME since excessive accumulation of mucosal tissue is seen in $\mathrm{TNFA}^{-1-}$ MEs both before and after bacterial inoculation of the ME.

\section{Methods}

\section{Animals}

6 week old female TNFA $^{-/-}$mice (B6;129S6- ${ }^{\text {Tnftm1Gkl }} / \mathrm{J}$ ) were obtained from Jackson Labs (Bar Harbor, ME) and housed under germ-free conditions. These mice are homozygous for a targeted mutation in the TNF gene (Tnfa, Tnfsf2, Tnftm1Gkl) and are therefore TNFA deficient [20,47]. Female B6;129SF2 mice served as WT controls. These mice provide a close match for the B6;129 background of the TNFA ${ }^{-1-}$ mice. All animal experimental procedures followed the appropriate $\mathrm{NIH}$ guidelines. They were reviewed and approved by the Institutional Animal Use and Care Committee of the San Diego VA Medical Center, protocol number 07-024.

\section{Bacteria}

Haemophilus influenzae strain 3655 (nontypeable, biotype II; NTHi) was used at a concentration of $10^{5}-10^{6}$ / $\mathrm{ml}$ to induce experimental OM. The inocula were prepared as previously described $[19,21]$.

\section{Surgery}

Anesthesia was induced by intraperitoneal injection of $0.4 \mathrm{ml}$ per $100 \mathrm{~g}$ bodyweight of a rodent cocktail containing $13.3 \mathrm{mg} / \mathrm{ml}$ ketamine $\mathrm{HCl}, 1.3 \mathrm{mg} / \mathrm{ml}$ xylazine and $0.25 \mathrm{mg} / \mathrm{ml}$ acepromazine maleat. The ME bullae were exposed bilaterally through a vertical midline incision on the neck. A 25 gauge syringe needle was used to fenestrate the center of the ME bullae. Via this opening, approximately 3-5 $\mu \mathrm{l}$ of NTHi $\left(10^{5} / \mathrm{ml}\right)$ was injected using an insulin syringe. Excess fluid was absorbed with a sterile cotton swab, the cervical tissue was replaced over the fenestrations and the skin incision stapled closed. The mice were allowed to survive for various intervals after inoculation.

\section{Gene Expression}

Expression of TNF and TNFR family genes was evaluated in WT mice by DNA microarray. Age-matched C57Bl/6:CB F1 hybrid mice were purchased from Jackson Laboratories (Bar Harbor, ME). Twenty mice per time point were inoculated bilaterally with Haemophilus influenzae strain 3655 (non-typeable, biotype II, originally isolated from an OM patient; NTHi), in $5 \mathrm{ml}$ at a concentration of $10^{5}-10^{6} / \mathrm{ml}$ as described previously $[19,21]$. Uninoculated, naive animals (time 0) served as controls. ME mucosae were harvested and combined at each of the following intervals: 0 (no treatment), 3 or 6 hours, as well as 1, 2, 3, 5 or 7 days after NTHi inoculation. The tissue was homogenized in TRIzol ${ }^{\mathrm{TM}}$ (Invitrogen, Carlsbad, CA) and total RNA was extracted. Total RNA quality was assessed using the RNA 6000 Labchip Kit on the Agilent 2100 Bioanalyzer for the integrity of $18 \mathrm{~S}$ and $28 \mathrm{~S}$ ribosomal RNA. The mRNA was reverse transcribed using a T7-oligodT primer then in vitro transcribed using T7 RNA polymerase to generate biotinylated cRNA probes that were hybridized to two Affymetrix MU430 2.0 microarrays per sample. This procedure was then duplicated for each time point to obtain a second, independent replication, for a total of 32 arrays for the controls and seven OM time points.

Expression of mRNA encoding caspases 3 and 4 was evaluated in $\mathrm{WT}$ and $\mathrm{TNFA}^{-/-}$mice using qPCR. Mice were inoculated with NTHi and sacrificed at intervals of 0 or 6 hours, as well as 1, 2, 5 or 10 days. The contents of at least $6 \mathrm{MEs}$ per time point and genotype were isolated. mRNA was extracted, reverse transcribed, and $1 \mathrm{mg} / \mathrm{ml}$ of cDNA was amplified using pre-developed TaqMan qPCR primers (Applied Biosystems, Foster 
City, CA) for caspase 3 (Mm01195084_m1) and caspase 4. (Mm00432307_m1) in an ABI Prism 7000 Sequence Detection System (Applied Biosystems). Fold induction was calculated using the comparative threshold cycle $(\mathrm{Ct})$ method [48]. Relative expression of each target gene was normalized to levels of GAPDH (Mm03302249_g1) and compared to uninfected mucosa.

\section{Histology}

The mice were sacrificed by intracardial perfusion with PBS and 4\% paraformaldehyde (PFA) under general anesthesia, 1, 2, 3, 5, 7 or 10 days after inoculation. The MEs were isolated and postfixed in 4\% PFA overnight. The ME bullae were decalcified for 14 days in EDTA and embedded in paraffin. Serial $7 \mu \mathrm{m}$ sections were stained with H\&E. Digital micrographs were taken from a standardized region of the ME of each specimen. The thickness of the epithelial and stromal layers of the mucosa was measured over approximately $500 \mu \mathrm{m}$ at a standard location in the plane of the Eustachian tube and computer-averaged.

For analysis of the number of inflammatory cells, digital micrographs were obtained from each specimen in the plane that displayed the maximum amount of cells in the ME cavity. The area covered by inflammatory cells as a percentage of a standard area in the ME cavity was then calculated using image analysis software.

\section{Apoptosis}

For TUNEL labeling, paraffin sections of each ear were deparaffinized and labeled with the "TACS" 2 TdTDAB In Situ Apoptosis Detection Kit" (Trevigen, Inc., Gaithersburg, MD) including positive and negative controls. The percentage of TUNEL positive cells was determined by enumerating 100 mucosal cells in three different planes in each specimen. Each ear was also examined for polyp formation in the ME mucosa in H\&E stained serial sections, as a measure of the accumulation of excess mucosal cells. The percentage of ears with polyps was calculated. All calculations were performed independently, by two observers, with matching results.

\section{Statistics}

For statistical evaluation of gene array data, raw intensity data was median normalized and statistical differences in gene transcript expression levels were evaluated using a variance-modeled posterior inference approach (VAMPIRE) [49]. Specific TNF and TNFR family genes were assessed at individual time points, after Bonferonni correction for multiple tests, using Genespring GX 7.3 (Agilent). To quantify differential gene expression, transcript hybridization levels were expressed as fold change relative to those obtained for uninfected control (0 hr) MEs.
In the text they have been described as up-regulated if they were significantly higher than control values, and down-regulated if they were significantly lower. To document statistical significance of morphological and cellular data, ANOVA was performed on all data using StatView 5.0 statistics calculation software. Differences between groups were considered significant at $\mathrm{p}<0.05$.

\section{Additional material}

Additional file 1: Table S1. Fold expression data derived from gene arrays, for the TNF and TNFR family genes presented graphically in Figure 1 , including variability (Range) and significance (P-value).

\section{Abbreviations}

Ct: comparative threshold cycle; ME: middle ear; KO: knockout; NTHi: nontypeable Haemophilus influenzae; OM: otitis media; PFA:

paraformaldehyde; TNFA: tumor necrosis factor $a$; TNFA ${ }^{-/}$mice: TNF-deficient (B6129S6-Tnftm1Gkl/J) mice; TNFR: TNF receptor; TNFsolRI: TNF soluble receptor type I; VAMPIRE: variance-modeled posterior inference; WT: wild-type mice, B6129SF2.

\section{Acknowledgements}

The authors would like to thank Marina Miller, Jae Y. Cho, Kirsti McElwain (Department of Medicine/Rheumatology, Allergy and Immunology, UCSD School of Medicine) and Sharon Okamoto (Department of Infectious Diseases, VA Medical Center, La Jolla, CA) for support and advice and Eduardo Chavez (Department of Surgery/Otolaryngology, UCSD School of Medicine) and Susanne Kanabey (Department of Otorhinolaryngology, RuhrUniversity of Bochum, Germany) for excellent technical assistance. This work was supported by NIH/NIDCD grants DC000129 (to A.F.R.), DC006279 (to S. W.) and Al38425, Al70535 \& Al72115 (to D.B.), the VA Research Service (A.F.R.) and by the German DFG (EB 260/1-1, to J.E.).

\section{Author details}

${ }^{1}$ Department of Otorhinolaryngology, Head and Neck Surgery Klinikum Bielefeld (Academic Teaching Hospital University of Münster), Bielefeld, Germany. ${ }^{2}$ Department of Surgery, Division of Otolaryngology, University of California, San Diego School of Medicine and Department of Veterans Affairs Medical Center, La Jolla, California, USA. ${ }^{3}$ Department of Medicine, Division of Rheumatology, Allergy and Immunology, UCSD School of Medicine, La Jolla, California, USA. ${ }^{4}$ Department of Obstetrics and Gynecology Städtische Klinikum Bielefeld (Academic Teaching Hospital University of Münster), Bielefeld, Germany.

\section{Authors' contributions}

$\mathrm{JE}$ and $\mathrm{AL}$ contributed to experimental design, performed the majority of the experiments, analyzed data and wrote the manuscript. $\mathrm{MH}$ and $\mathrm{KP}$ assisted with knockout mouse and gene array experiments and data analysis. UE participated in animal surgery and preparation of histologic specimens. JH performed gene array data analysis. DB provided advice on experimental design. HS assisted in histology, participated in composing the manuscript and gave advice in data interpretation. AFR and SIW designed the study, provided overall supervision, assisted with data analysis and interpretation, and made substantive contributions to writing the manuscript. All authors read and approved the final manuscript.

Received: 2 November 2010 Accepted: 26 January 2011

Published: 26 January 2011

\section{References}

1. Chen G, Goeddel DV: TNF-R1 signaling: a beautiful pathway. Science 2002, 296:1634-1635.

2. Sands BE: Why do anti-tumor necrosis factor antibodies work in Crohn's disease? Rev Gastroenterol Disord 2004, 4(Suppl 3):S10-S17. 
3. Pimentel-Muinos FX, Seed B: Regulated commitment of TNF receptor signaling: a molecular switch for death or activation. Immunity 1999, 11:783-793.

4. Mathew SJ, Haubert D, Krönke M, Leptin M: Looking beyond death: a morphogenetic role for the TNF signalling pathway. J Cell Sci 2009, 122:1939-1946.

5. Aggarwal BB: Signalling pathways of the TNF superfamily: a doubleedged sword. Nat Rev Immunol 2003, 3:745-756.

6. Smirnova MG, Kiselev SL, Gnuchev NV, Birchall JP, Pearson JP: Role of the pro-inflammatory cytokines tumor necrosis factor-alpha, interleukin-1 beta, interleukin- 6 and interleukin- 8 in the pathogenesis of the otitis media with effusion. Eur Cytokine Netw 2002, 13:161-172.

7. Barzilai A, Dekel B, Dagan R, Passwell JH, Leibovitz E: Cytokine analysis of middle ear effusions during acute otitis media: significant reduction in tumor necrosis factor alpha concentrations correlates with bacterial eradication. Pediatr Infect Dis J 1999, 18:301-303.

8. Yellon RF, Doyle WJ, Whiteside TL, Diven WF, March AR, Fireman P: Cytokines, immunoglobulins, and bacterial pathogens in middle ear effusions. Arch Otolaryngol Head Neck Surg 1995, 121:865-869.

9. Okamoto Y, Kudo K, Ishikawa K, Ito E, Togawa K, Saito I, Moro I, Patel JA Ogra PL: Presence of respiratory syncytial virus genomic sequences in middle ear fluid and its relationship to expression of cytokines and cell adhesion molecules. J Infect Dis 1993, 168(5):1277-1281.

10. Skotnicka B, Hassmann E: Cytokines in children with otitis media with effusion. Eur Arch Otorhinolaryngol 2000, 257:323-326.

11. Melhus A, Ryan AF: Expression of cytokine genes during pneumococcal and nontypeable Haemophilus influenzae acute otitis media in the rat. Infect Immun 2000, 68:4024-4031.

12. Leichtle A, Hernandez M, Ebmeyer J, Yamasaki K, Lai Y, Radek K, Choung YH, Euteneuer S, Pak K, Gallo R, Wasserman SI, Ryan AF: CC chemokine ligand 3 overcomes the bacteriocidal and phagocytic defect of macrophages and hastens recovery from experimental otitis media in TNF-/- Mice. J Immunol 2010, 184:3087-3097.

13. Lin J, Haruta A, Kawano H, Ho SB, Adams GL, Juhn SK, Kim Y: Induction of mucin gene expression in middle ear of rats by tumor necrosis factoralpha: potential cause for mucoid otitis media. J Infect Dis 2000, 182:882-887

14. Catanzaro A, Ryan A, Batcher S, Wasserman SI: The response to human rIL1, rlL-2, and rTNF in the middle ear of guinea pigs. Laryngoscope 1991, 101:271-275.

15. Lee DH, Park YS, Jung TT, Yeo SW, Choi YC, Jeon E: Effect of tumor necrosis factor-alpha on experimental otitis media with effusion. Laryngoscope 2001, 111:728-733.

16. Bernstein JM: The molecular biology of nasal polyposis. Curr Allergy Asthma Rep 2001, 1:262-267.

17. Jacobson-Brown P, Neuman MG: Colon polyps and cytokines: emerging immunological mechanisms. Rom J Gastroenterol 2003, 12:207-214.

18. Rivkin AZ, Palacios SD, Pak K, Bennett T, Ryan AF: The role of Fas-mediated apoptosis in otitis media: observations in the Ipr/lpr mouse. Hear Res 2005, 207:110-116.

19. Melhus A, Ryan AF: A mouse model for acute otitis media. Apmis 2003, 111:989-994.

20. Ryan AF, Ebmeyer J, Furukawa M, Pak K, Melhus A, Wasserman SI, Chung WH: Mouse models of induced otitis media. Brain Res 2006, 1091:3-8.

21. Hernandez M, Leichtle A, Pak K, Ebmeyer J, Euteneuer S, Obonyo M, Guiney DG, Webster NJ, Broide DH, Ryan AF, Wasserman SI: Myeloid differentiation primary response gene 88 is required for the resolution of otitis media. J Infect Dis 2008, 198:1862-1869.

22. Ebmeyer J, Furukawa M, Pak K, Ebmeyer U, Sudhoff H, Broide D, Ryan AF, Wasserman S: Role of mast cells in otitis media. J Allergy Clin Immunol 2005, 116:1129-1135.

23. Kamada S, Washida M, Hasegawa J, Kusano H, Funahashi $Y$, Tsujimoto $Y$ : Involvement of caspase-4(-like) protease in Fas-mediated apoptotic pathway. Oncogene 1997, 15:285-290.

24. Mao ZG, Jiang CC, Yang F, Thorne RF, Hersey P, Zhang XD: TRAIL-induced apoptosis of human melanoma cells involves activation of caspase-4. Apoptosis 2010, 15:1211-1222.

25. Pitti RM, Marsters SA, Ruppert S, Donahue CJ, Moore A, Ashkenazi A: Induction of apoptosis by Apo-2 ligand, a new member of the tumor necrosis factor cytokine family. J Biol Chem 1996, 271:12687-126890.
26. Wiley SR, Schooley K, Smolak PJ, Din WS, Huang CP, Nicholl JK, Sutherland GR, Smith TD, Rauch C, Smith CA, et al: Identification and characterization of a new member of the TNF family that induces apoptosis. Immunity 1995, 3:673-682.

27. Alderson MR, Smith CA, Tough TW, Davis-Smith T, Armitage RJ, Falk B, Roux E, Baker E, Sutherland GR, Din WS: Molecular and biological characterization of human 4-1BB and its ligand. Eur J Immunol 1994, 24:2219-2227.

28. Kang YJ, Kim SO, Shimada S, Otsuka M, Seit-Nebi A, Kwon BS, Watts TH, Han J: Cell surface 4-1BBL mediates sequential signaling pathways 'downstream' of TLR and is required for sustained TNF production in macrophages. Nat Immunol 2007, 8:601-609.

29. Vitovski S, Phillips JS, Sayers J, Croucher PI: Investigating the interaction between osteoprotegerin and receptor activator of NF-kappaB or tumor necrosis factor-related apoptosis-inducing ligand: evidence for a pivotal role for osteoprotegerin in regulating two distinct pathways. J Biol Chem 2007, 282:31601-31609.

30. Matsui H, Hikichi Y, Tsuji I, Yamada T, Shintani Y: LIGHT, a member of the tumor necrosis factor ligand superfamily, prevents tumor necrosis factor-alpha-mediated human primary hepatocyte apoptosis, but not Fas-mediated apoptosis. J Biol Chem 2002, 277:50054-50061.

31. Zhai Y, Guo R, Hsu TL, Yu GL, Ni J, Kwon BS, Jiang GW, Lu J, Tan J, Ugustus M, Carter K, Rojas L, Zhu F, Lincoln C, Endress G, Xing L, Wang S, Oh KO, Gentz R, Ruben S, Lippman ME, Hsieh SL, Yang D: LIGHT, a novel ligand for lymphotoxin beta receptor and TR2/HVEM induces apoptosis and suppresses in vivo tumor formation via gene transfer. J Clin Invest 1998, 102:1142-1151

32. Godfrey WR, Fagnoni FF, Harara MA, Buck D, Engleman EG: Identification of a human OX-40 ligand, a costimulator of CD4+ T cells with homology to tumor necrosis factor. J Exp Med 1994, 180:757-762.

33. Schneider P, MacKay F, Steiner V, Hofmann K, Bodmer JL, Holler N, Ambrose C, Lawton P, Bixler S, Acha-Orbea H, Valmori D, Romero P, Werner-Favre C, Zubler RH, Browning JL, Tschopp J: BAFF, a novel ligand of the tumor necrosis factor family, stimulates B cell growth. J Exp Med 1999, 189:1747-1756.

34. Gurney AL, Marsters SA, Huang RM, Pitti RM, Mark DT, Baldwin DT, Gray AM, Dowd AD, Brush AD, Heldens AD, Schow AD, Goddard AD, Wood WI, Baker KP, Godowski PJ, Ashkenazi A: Identification of a new member of the tumor necrosis factor family and its receptor, a human ortholog of mouse GITR. Curr Biol 1999, 9:215-218.

35. Kwon B, Yu KY, Ni J, Yu GL, Jang IK, Kim YJ, Xing L, Liu D, Wang SX, Kwon BS: Identification of a novel activation-inducible protein of the tumor necrosis factor receptor superfamily and its ligand. J Biol Chem 1999, 274:6056-6061.

36. Eby MT, Jasmin A, Kumar A, Sharma K, Chaudhary PM: TAJ, a novel member of the tumor necrosis factor receptor family, activates the c-Jun $\mathrm{N}$-terminal kinase pathway and mediates caspase-independent cell death. J Biol Chem 2000, 275:15336-15342.

37. Emery JG, McDonnell P, Burke MB, Deen KC, Lyn S, Silverman C, Dul E, Appelbaum ER, Eichman C, DiPrinzio R, Dodds RA, James IE, Rosenberg M, Lee JC, Young PR: Osteoprotegerin is a receptor for the cytotoxic ligand TRAIL. J Biol Chem 1998, 273:14363-1437.

38. Clark L, Wei M, Cattoretti G, Mendelsohn C, Tycko B: The Tnfrh1 (Tnfrsf23) gene is weakly imprinted in several organs and expressed at the trophoblast-decidua interface. BMC Genet 2002, 3:11.

39. Tone M, Tone Y, Fairchild PJ, Wykes M, Waldmann H: Regulation of CD40 function by its isoforms generated through alternative splicing. Proc Natl Acad Sci USA 2001, 98:1751-1756.

40. Wiley SR, Cassiano L, Lofton T, Davis-Smith T, Winkles JA, Lindner V, Liu H, Daniel TO, Smith CA, Fanslow WC: A novel TNF receptor family member binds TWEAK and is implicated in angiogenesis. Immunity 2001, 15:837-846.

41. Ahlgren S: Cell division, differentiation, and death in avian embryos. Methods Cell Biol 2008, 87:153-165.

42. Ryan AF, Catanzaro A, Wasserman SI, Harris JP: Secondary immune response in the middle ear: immunological, morphological, and physiological observations. Ann Otol Rhinol Laryngol 1986, 95:242-249.

43. Mayer B, Oberbauer R: Mitochondrial regulation of apoptosis. News Physiol Sci 2003, 18:89-94.

44. Riedl SJ, Shi Y: Molecular mechanisms of caspase regulation during apoptosis. Nat Rev Mol Cell Biol 2004, 5:897-907. 
45. Fox S, Leitch AE, Duffin R, Haslett C, Rossi AG: Neutrophil apoptosis: relevance to the innate immune response and inflammatory disease. J Innate Immun 2:216-227.

46. Koizumi K, Poulaki V, Doehmen S, Welsandt G, Radetzky S, Lappas A, Kociok N, Kirchhof B, Joussen AM: Contribution of TNF-alpha to leukocyte adhesion, vascular leakage, and apoptotic cell death in endotoxininduced uveitis in vivo. Invest Ophthalmol Vis Sci 2003, 44:2184-2191.

47. Pasparakis M, Alexopoulou L, Episkopou V, Kollias G: Immune and inflammatory responses in TNF alpha-deficient mice: a critical requirement for TNF alpha in the formation of primary B cell follicles, follicular dendritic cell networks and germinal centers, and in the maturation of the humoral immune response. J Exp Med 1996, 184:1397-1411.

48. Schauber J, Dorschner RA, Coda AB, Büchau AS, Liu PT, Kiken D, Helfrich YR, Kang S, Elalieh HZ, Steinmeyer A, Zügel U, Bikle DD, Modlin RL, Gallo RL: Injury enhances TLR2 function and antimicrobial peptide expression through a vitamin D-dependent mechanism. J Clin Invest 2007, 117:803-811.

49. Hsiao A, Ideker T, Olefsky JM, Subramaniam S: VAMPIRE microarray suite: a web-based platform for the interpretation of gene expression data. Nucleic Acids Res 2005, , 33 Web Server: W627-W632.

doi:10.1186/1471-2172-12-12

Cite this article as: Ebmeyer et al: TNFA deletion alters apoptosis as well as caspase 3 and 4 expression during otitis media. BMC Immunology 2011 12:12.

\section{Submit your next manuscript to BioMed Central} and take full advantage of:

- Convenient online submission

- Thorough peer review

- No space constraints or color figure charges

- Immediate publication on acceptance

- Inclusion in PubMed, CAS, Scopus and Google Scholar

- Research which is freely available for redistribution

Submit your manuscript at www.biomedcentral.com/submit 